\title{
El Quijote de Avellaneda y la reorientación ideológica de los personajes centrales: un estudio de su desenlace
}

\author{
John O’KuinghtTons RodRíGueZ \\ Universidad de São Paulo ${ }^{1}$
}

Resumen: Este trabajo objetiva identificar y comentar los contenidos ideológicos que se encuentran implícitos en el último capítulo del Quijote de Avellaneda, para lo cual se tendrán en cuenta algunas de las líneas ideológicas que caracterizan el pensamiento de Cervantes. Adjunto a ello se analizarán las correspondencias que es posible determinar entre el conjunto de representaciones sociales y los patrones de comportamiento de los dos personajes centrales de la continuación. Como criterio de base seguiremos las definiciones de ideología y de representaciones sociales propuestas por van Dijk (1999), complementadas con sendas contribuciones de Riorda y Farré (2012) y Žižek (2013).

Palabras clave: Don Quijote; Sancho; Avellaneda; ideología; representaciones sociales

Avellaneda's Quixote and the ideologycal re-orientation of the central characters: an analysis of the novel's ending

Abstract: This paper aims at identifying and commenting the ideological contents that can be found in the final chapter of Avellaneda's Quixote, considering some of the ideological foundations that define Cervantes' thought. At the same time, I will analyze the relations between the ideological bases and the behaviour patterns that characterize the two central imitative characters. As a theoretical background, I will adopt the concepts of ideology and social representations according to van Dijk (1999), as well as some contributions taken from the works of Riorda and Farré (2012) and Žižek (2013).

Keywords: Quixote; Sancho; Avellaneda; ideology; social representations

1 Grupo de Estudios Cervantes. 


\section{INTRODUCCIÓN}

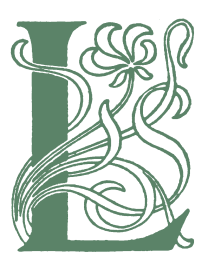

as directrices ideológicas ${ }^{2}$ de las novelas aquí citadas suelen manifestarse de manera imbricada en el tejido de las aventuras. Para el examen del sistema de representaciones sociales dominante en Avellaneda hemos seguido algunas de las aportaciones de James Iffland, quien identifica un elocuente sustrato de connivencia ideológica conservadora a lo largo de la continuación. En un trabajo de relieve ${ }^{3}$, este autor se pregunta qué aspectos concretos del Quijote cervantino incomodaron tanto a Avellaneda al punto de llevarlo a emprender su refutación ideológica, la cual, a nuestro entender, no significó ni implicó una falsificación de su modelo ${ }^{4}$. La ojeriza que le provocó la obra lo incitó, en consecuencia, a reorientar el Quijote original y a dirigirlo hacia un ámbito de creencias que consideraba seguro y libre de amenazas 5 .

2 Para demarcar una definición de ideología que sea operativa y coherente para nuestro análisis es necesario advertir que su contenido es de muy ardua aprehensión. Slavoj Žižek, por ejemplo, ha señalado que lo mismo puede designar «desde una actitud contemplativa que desconoce su dependencia en relación a la realidad social, hasta un conjunto de creencias dirigido a la acción» [traducción propia] (Žižek, 2013: 9). En un espacio más acotado, Riorda y Farré (2012) subrayan el aspecto político del término, adscribiendo a la idea de que ideología apunta al conjunto instrumental de teorías y propuestas que conforman un programa socio político.

Por su pertinencia y concisión, en este análisis seguiremos el delineamiento de van Dijk, quien sostiene que «Las ideologías se pueden definir sucintamente como la base de las representaciones sociales compartidas por los miembros de un grupo. Esto significa que las ideologías les permiten a las personas, como miembros de un grupo, organizar la multitud de creencias sociales acerca de lo que sucede, bueno o malo, correcto o incorrecto, según ellos, y actuar en consecuencia». (Dijk, 1999: 21).

3 Nos referimos a De fiestas y aguafiestas: risa, locura e ideología en Cervantes y Avellaneda, (1999).

4 Sobre esta reacción y la contra-respuesta cervantina, vale tener en cuenta perspectivas como la de Hanno Ehrlicher, quien, junto con advertir sobre el riesgo de «denunciar la 'didactización' o 'ideologización' del Quijote de Cervantes como una falsificación del original», vindica «la fuerza productiva que tuvo ese modelo de narración alternativo». La acusación de falsificación devalúa, claro está, los méritos propios de la obra, de los que ciertamente no carece. A lo anterior, Ehrlicher añade: «Para Cervantes fue un acicate que lo estimuló a proseguir su propio artificio narrativo exponiéndolo y reflexionándolo en la narración de una forma todavía más consciente» (Ehrlicher, 2016:63). En el mismo derrotero, Álvarez Roblin ha considerado que para validar su estatura creativa «Cervantes tiene que reivindicar su diferencia con respecto a su imitador y esto pasa en varias ocasiones por un mecanismo inversivo, que concierne en gran medida a los protagonistas, pero que también afecta la trama de la novela.» (Álvarez Roblin, 2016:99). A renglón seguido, el autor añade esta lúcida reflexión: «Es un lugar común en la crítica considerar que el autor original supera sobradamente a su competidor y triunfa sobre él (...), pero nunca se ha planteado en profundidad la cuestión de saber si, al fin y al cabo, Cervantes consigue o no diferenciarse realmente de su contrincante. » (Álvarez Roblin, 2016:100).

5 Javier Blasco ha comentado oportunamente esta conclusión del citado autor: «Avellaneda no sólo continúa la historia de don Quijote, sino que la enmienda y transforma y, en expresión de Iffland (que considero muy acertada) la secuestra, transformándola en una cosa totalmente distinta a la "inventada" por Cervantes» (Blasco, 2005:1-2) 
Paralelamente y a modo complementario de esta interrogante, otro estudioso, Luis Gómez Canseco ha señalado que Avellaneda no debió pensar en objetivos precisos para poner en cortapisa a su antecesor, sino que debió actuar por un mero "golpe de bilis".

Aunque disímiles, creemos, no obstante, que ambas posiciones no son incompatibles. Desde el punto de vista de las motivaciones, el golpe de bilis a que alude el autor también remite a un objetivo. Ello refuerza la idea de que el Quijote de 1614 fue concebido y luego ejecutado como una contestación y que -conforme el mismo Gómez Canseco e Iffland sustentan- en este tránsito hubo implicaciones ideológicas que dieron contenido y coherencia a la novela.

\section{AD PORTAS DEL FINAL}

Es bien conocida la forma como Alonso Fernández de Avellaneda dio término a la historia de su Quijote. Y no lo es menos la manera como Cervantes impidió la probabilidad de nuevas apropiaciones ultimando a su personaje medular.

El desenlace ideado por el primero difiere del cervantino en tres vértices fundamentales:

a) la preservación de la vida de don Quijote;

b) la apertura del libro para una posible continuación;

c) los intersticios ideológicos que se desprenden del internamiento del caballero.

De inicio, vale acotar que para el examen de los pormenores que dan cuenta del encierro del segundo don Quijote nos atendremos a lo que el propio Avellaneda deja colegir de la condición institucional y los métodos correctivos aplicados en el Nuncio de Toledo, pues entendemos que su descripción corresponde a una opinión no poco representativa que en la época se tenía sobre la realidad del establecimiento ${ }^{6}$.

6 Hacemos esta salvedad siguiendo la precaución que recomienda sobre el tema el médico psiquiatra e historiador de la medicina toledana Rafael Sancho de San Román, director de la Real Academia de Toledo 
Para situarnos y valorar apropiadamente este aspecto recordemos el ámbito en que se inscribe el episodio final. El capítulo XXXV, el penúltimo de la historia y que prologa el confinamiento del héroe, se ordena en torno a la vigilia del matrimonio que contraerá la hermana de don Carlos. Desde el punto de vista ideológico, esta parte comporta una relevancia decisiva, pues en ella se reconocen con énfasis los adjetivos sociales que se han atribuido a lo largo de toda la novela al amo y su escudero. De ser posible, cifraríamos la idea anterior en una irónica (y cínica, cabría agregar) frase proferida por el citado aristócrata -«el deseo que de vuestro bien he tenido» (Avellaneda, 2005: 693)-, según consta en el parlamento que abre el capítulo y que se refiere a la opinión que desde un inicio el noble ha guardado de Sancho:

Ya sabéis, mi buen Sancho, el deseo que de vuestro bien he tenido desde que os vi en Zaragoza y el cuidado con que os regalé de mi mano en la mesa la primer noche que entrastes en mi casa, y cuánta merced os han hecho siempre en ella mis criados, particularmente el cocinero cojo. (Avellaneda, 2005: 693)

Esta sucinta intervención resume no solo el aparato de burlas desplegado por los caballeros, sino también la constitución jerárquica de la ideología de dominio que defienden. En efecto, mediante esta declaración el noble -y todo el grupo que representa- finge preocuparse del bien ajeno cuando en realidad no pretende más que anclar físicamente a los personajes en su territorio de esparcimiento. Sugiere, asimismo, que al mundo inferior y risible de don Quijote y Sancho solo se puede acceder mediante la representación fingida, que implica tanto el respeto simulado hacia el otro como el ocultamiento de las intenciones y las obras. De esta afectación planificada los señores salen indemnes de todo juicio o comentario adverso por parte del narrador y aun del resto de personajes que conforman la ficción pues se entiende que se trata de una acción derivada de un derecho constitutivo.

El comentario de don Carlos conduce a la explicitación del destino mismo de Sancho, que junto al de otros personajes, ha sido sellado de manera deliberada. Mientras Bárbara es encaminada a una casa de mujeres virtuosas,

entre 1979 y 1984, quien afirma que la mala imagen del hospicio difundida por los cronistas de la época (entre ellos el propio Avellaneda) representa en cierta medida a la llamada opinión pública. Aun cuando Román no niega las sombras del establecimiento, vindica también sus aportes y recomienda cautela a la hora de censurar sin matices a la institución. 
reducto de prostitutas arrepentidas ${ }^{7}$, y Sancho y su esposa son llevados a oficiar de bufones en la corte del Archipámpano, don Quijote es recluido en un nosocomio para orates. A Sancho se le prometen dos años de salario adelantado y se le advierte de que al llegar a la corte habrá de vestirse al uso que demanda su nuevo desempeño. Al conocer la propuesta, el escudero responde con el tópico del desprecio de corte y alabanza de aldea con no poca convicción:

[...] volverme yo a mi casa y quitarme de aquestos cuentos [...] desde agora renuncio todos los derechos y pertinencias que en cuanto conquistare me pueden pertenecer por herencia o tema de juicio, y me determino volver a mi tierra agora que viene la sementera. (Avellaneda, 2005: 696)

No obstante, aquello que se inicia con una bravata («[...] lo que son salarios se paga muy mal [...] dicen los pícaros de la cocina que la vida de palacio es vida bestial, do se vive de esperanzas y se muere en algún hospital» (Avellaneda, 2005: 697), a poco andar declina y decae a esta imprevista afirmación:

[...] si el señor Archipámpanos me asegurase un ducado cada mes y dos o tres pares de zapatos por un año, con cédula de que no me lo había de poner después en pleito, y vuestra merced saliese por fianza de ello, sin duda ternía mozo en mí para muchos días. (Avellaneda, 2005: 697)

El atuendo que Sancho vindica para oficiar sus nuevas funciones es no poco simbólico. Don Carlos le pide que se cale un sombrero como impone la usanza de la corte, pero el escudero, no solo no lo acepta, sino que defiende la propiedad de su caperuza, que es el signo distintivo de los bufones ${ }^{8}$. En otras palabras, a estas alturas el escudero ha incorporado definitivamente el destino que le habían maquinado diversas mentes ajenas. Ello confirma la idea de que a lo largo de la ficción ninguno de los personajes signados como materia de esparcimiento -Bárbara, don Quijote y Sancho- han sido dueños efectivos de sus respectivas decisiones, sino todo lo contrario.

\footnotetext{
7 No es irrelevante mencionar el probable guiño que guarda este destino con el de Mariana, cuñada del soldado aragonés Jerónimo Pasamonte, quien pide sin conseguirlo que la ingresen a una de estas instituciones. Entre otros, Martín Jiménez (2005) ha recordado este episodio para postular que Pasamonte y Avellaneda eran la misma persona.

8 Sobre este signo vale comentar que «la caperuza es definida por Márquez Villanueva como el “jeroglífico de la locura y prenda distintiva o de rigueur para el loco de la corte" » (Iffland, 1999: 333).
} 


\section{LOS RUMBOS DE DON QUIJOTE Y SANCHO}

Acaso sea la separación y desconocimiento final mutuos entre amo y escudero lo que con mayor y más triste distancia diferencia la novela imitativa de la de su modelo. El hiato terminal entre los personajes se va anunciando con cierto grado a partir de un reclamo que Sancho profiere contra la violencia que implicaba su condición de escudero":

[...] yo le hablaré claro antes que vaya a Toledo, y le volveré su rucio, la maleta y juntamente el desaforado guante del gigante Bramidán (...) Que yo no quiero nada de nadie; y más que le diré se vaya con Dios, pues desde aquí al día del juicio reniego de las peleas, sin querer más cosa con ellas, pues tan pelado y apaleado salgo de sus uñas, cual saben mis pobres espaldas. (Avellaneda, 2005: 702-703).

Este reniego ya había sido inculcado por el Archipámpano cuando a propósito de las excentricidades del caballero declaró: «sus locuras, desatinos y arrojamientos no pueden prometer buen suceso a él ni a quien se le acompañe» (Avellaneda, 2005: 694). Esta devaluación del compañerismo queda rubricada con la entrada de Sancho y su mujer al ámbito de la corte y la promesa de continuación de las aventuras caballerescas en otro libro: «Los sucesos destos buenos y cándidos casados remito a la historia que dellos se hará andando el tiempo, pues son tales, que piden de por sí un copioso libro» (Avellaneda, 2005: 704). Tal anuncio, que podría ser simple émulo de la eventualidad de una continuación estipulada por Cervantes al final de I, 52 parece ser mucho más que una réplica retórica ${ }^{10}$. En efecto, como arguye Iffland, la secuela con las peripecias de Sancho gana sentido si se toma en cuenta la línea ideológica que esconde la comedia según el marco sugerido por Avellaneda: relativizar y aun abolir las aspiraciones de movilidad social.

La separación de la pareja se efectúa de un modo que debió haber resentido profundamente a Cervantes. Los personajes no solo no se despiden, sino

\footnotetext{
9 Probablemente el primer indicio de este alejamiento conste en el capítulo III, en el que don Quijote convierte a Sancho en un gigante al que persigue dando espadazos indiscriminados.

10 La declaración de una continuidad evidencia que Avellaneda conocía bien los tópicos de composición de los libros de caballerías, los que en sus desenlaces dejaban en abierto la probabilidad de nuevos vástagos. Gutiérrez Trápaga lo ha resumido del siguiente modo: «Avellaneda reconoció claramente el modelo de los libros de caballerías utilizado por Cervantes, mismo que él también imitó para presentar su obra como heredera legítima del Quijote de 1605» (Gutiérrez Trápaga, 2016: 144)
} 
que incluso se desconocen, como si nunca hubieran tenido el mínimo intercambio, despojados de toda empatía, dignidad y reconocimiento mutuo: «Salióse el paje de la sala, y con él los demás, yéndose todos a sus camas, sin reparar don Quijote más en Sancho que si nunca le hubiera visto» (Avellaneda, 2005: 708). El dúo se encontrará nuevamente, pero con un revestimiento afectivo árido y disonante del que nos acostumbró Cervantes. La ruptura, empero, es coherente con la línea de comportamiento que se ha ido trazando en la imitación desde su albor.

El tipo de convivencia entre el amo y escudero originales no debió pasar inadvertido para Avellaneda, pues, bajo su pluma, la relación de ambos tomó visos acentuadamente diferenciadores. Aun cuando Avellaneda haya emulado los cauces dialógicos de los protagonistas, no los empleó para la edificación mutua de sus personalidades, sino para el encuadramiento a los signos retóricos delineados por su modelo. Como lo apunta Martín Jiménez (2000), el epígono se vale de las normas formales de construcción discursiva, según lo demuestran, por ejemplo, el episodio del melonar -en el que, recurriendo al discurso deliberativo previsto en la Retórica aristotélica, los personajes tratan de convencerse mutuamente de la validez de sus intenciones (don Quijote de su propósito de ganar fama; Sancho de su empeño por disuadirlo de entrar a una acción suicida)- o el intento persuasivo de don Carlos para que el escudero abandone a su amo y sirva al Archipámpano. A pesar de estas y otras evidencias ${ }^{11}$ los discursos retóricos ejecutados por Avellaneda jamás alcanzan la articulación que resulta de los diálogos cervantinos, los cuales, como defiende Martín Jiménez (2000), son fundamentales para el ejercicio de la pluralidad y de las diferentes visiones que los personajes tienen de la realidad. Las consecuencias visibles de este uso divergente del entramado dialogal son que los héroes de la imitación difícilmente se escuchan, Sancho no admira a su amo y queda anulado el aprendizaje compartido.

Como sostiene Martín Morán (2016), las diferencias en el manejo de los diálogos entre los autores rivales se corresponden con una congruente distancia en la ideación de los personajes: « [...] para Cervantes, diciéndolo con dos conceptos de Unamuno, han de tener personalidad, es decir, los contenidos

\footnotetext{
11 Entre estas vale mencionar las descripciones del amanecer y la referencia explícita a la dispositio valorada como mérito de la narración efectuada por el soldado Bracamonte: «[...] si bien todos alabaron al curioso soldado de la buena disposición de la historia y de la propiedad y honestidad con que había tratado cosas que de sí eran algo infames» (Avellaneda, 2005: 446)
} 
necesarios para poder relacionarse con los demás; para Avellaneda, basta que tengan individualidad, o sea, la capacidad de separarse de los otros.» (Martín Morán, 2016:75). A lo anterior el autor agrega:

[...] Avellaneda usa el diálogo en función de caracterizador de los personajes para construir entidades efectistas, autojustificadas en su plenitud lingüística sin vínculos con la acción diegética, cargadas de individualidad, pero sin la profundidad ni la personalidad para afrontar desde varias posiciones los casos del mundo, como en cambio hacen los personajes cervantinos. (2016:78).

Sobre el cotejo de los signos retóricos utilizados por ambos novelistas, Martín Jiménez sostiene que es posible colegir conclusiones bien definidas, según apunta en el siguiente fragmento:

La comparación de los dos Quijotes a la luz de la retórica de la época muestra que Cervantes no sólo no era un ingenio lego en la materia, sino que la conocía y la dominaba a la perfección, y que, basándose en las teorías de Huarte de San Juan, construyó la personalidad de don Quijote como la de un ser excepcional y un perfecto orador. Avellaneda, en cambio, convierte a don Quijote en un personaje ridículo incapaz de hilvanar un discurso mínimamente coherente. Esta elección satírica, que ni siquiera mantiene la hilaridad a causa de su monotonía, priva al personaje de las altas dotes de humanidad del don Quijote cervantino. (Martín Jiménez, 2000: 188)

Si bien Avellaneda no aprovechó las propiedades retóricas del mismo modo que su modelo, es admisible pensar que, más que por una medianía de talento, ello da fe de un propósito diagonal al que se desprende de las páginas cervantinas, y es que probablemente los personajes nucleares no pueden dialogar con encumbramientos porque, como adelantamos, sus respectivos sinos han sido ideológicamente prefigurados desde un principio. En el desenlace de la imitación se corona y se consolida la dilatada mengua de disquisiciones dialécticas entre ambos personajes. Este aminoramiento de las modulaciones retóricas, insistimos, más que a la capacidad compositiva de su autor, pueden adjudicarse a ciertos intereses ideológicos condicionantes: la abolición de las pretensiones de movilidad social y la consagración de las jerarquías sociales. 


\section{EL LOCO ERUDITO}

Establecido Sancho en la corte, don Quijote es conducido, mediante engaños, al destino que don Álvaro le atribuye desde que lo conoce: el internamiento. Los primeros que lo reciben en las proximidades del Nuncio de Toledo son los niños, que operan como una suerte de vértices sociales represores y castigadores. Al ingresar al hospicio, el caballero inquiere por la condición de los internos («[...] ¿por qué están aquí estos hombres presos, y algunos con tanta alegría?» (Avellaneda, 2005: 710)), emulando así la inquietud que su modelo vocaliza en el episodio de los galeotes, y que más tarde se formalizará con la orden expresa de liberación del loco cautivo: " [...] traedme vos, que estáis con ese caldero en la mano, las llaves luego de este aposento, y dejad salir libre, sano y salvo dél a este gran sabio, porque así es mi voluntad» (Avellaneda, 2005: 717). En un principio, el extravagante personaje condice con el arquetipo que conjuga en una misma identidad vesania y equilibrio mental. Al presentarse, el cautivo declara ser versado en ciencias tan diversas como teología, filosofía, medicina, astrología, leyes, retórica, poesía y música, para luego explayarse en un disperso catálogo de citas que trata de tópicos tan misceláneos como lo son la fragilidad del poder, el juicio de los hombres, la poesía frente a la historia, el recato, la condición femenina, la debilidad de las jóvenes y el desprecio a los bienes materiales.

El loco erudito, señala Gómez Canseco (Avellaneda, 2014: 41), halla antecedente literario en los locos filósofos y latinistas que encontramos en el libro IV de El peregrino en su patria, de Lope, que por su parte proceden de una antigua tradición que tornó compatibles la insania y el raciocinio fundado ${ }^{12}$. Sobre esta tradición, Foucault (2010) señala que en la época clásica la locura y la razón guardan una relación reversible, lo que implica que cada una es medida por la injerencia de la otra. La locura es, pues, una de las formas de la razón, al extremo que el autor inquiere «[...] ¿cómo distinguir, en una acción sabia que ha sido cometida por un loco, y en la más insensata de las locuras, que es obra de un hombre ordinariamente sabio y comedido?» (Foucault, 2010: 60). El loco, añade, tiene el poder de recordarle a cada uno su verdad y cuando se expresa «reivindica una posición más cercana a la felicidad y a la verdad que la razón, más cercana a la razón que a la misma razón» (Foucault, 2010: 29).

12 Al momento de erigir este personaje, Avellaneda debió tener en mente un medio pedagógico de signo contrarreformista. Gómez Canseco ha señalado que este marco es el de la Ratio studiorum jesuita. 
Históricamente, esta percepción sublimada de la locura quedará devaluada por la imagen oriunda del poder estatal que en el siglo XVI ya emparenta al loco con pobres, mendigos y delincuentes, todos ellos acusados de inutilidad y de inacción productiva. Consagrada esta percepción, la locura pasará a ser entendida como un problema social, desprovista de las luces de trascendencia de que estuvo revestida antes. Bajo este orden de cosas, el insano pasa a asumir dos destinos posibles: servir como objeto de lujo o la reclusión.

El confinamiento a que aludimos posee un largo tránsito desde la Edad Media. Foucault señala que, desaparecida la lepra como objetivo de exclusión, la discriminación recaerá sobre los padecimientos venéreos, pero también se transferirá a los sanos, a pobres, vagabundos o a muchachos de correccional. El internamiento procuraba, pues, una supuesta depuración de la convivencia social y de la imagen del estado. Las burlas públicas contra los locos no eran, por lo demás, infrecuentes:

[...] En ocasiones, algunos locos eran azotados públicamente, y como una especie de juego los ciudadanos los perseguían simulando una carrera, y los expulsaban de la ciudad golpeándolos con varas. Señales, todas estas, de que la partida de los locos era uno de tantos exilios rituales. (Foucault, 2010: 24-25)

Ejemplo de esta representación social es el Hôpital Général, fundado en 1656, y que corona un orden que se ha ido fraguando desde mucho antes ${ }^{13}$. Como arguye el mismo autor, dicho recinto no operaba como establecimiento médico, sino como entidad administrativa, con facultad para decidir, juzgar y ejecutar. El objetivo inicial del Hôpital Général fue impedir la circulación de 'ociosos' como pobres y mendigos, a quienes se acusa no solamente con imputaciones civiles como el desorden, sino también morales. La institución, agrega, posee estatuto ético y a sus regentes se les ha «confiado todo el aparato jurídico y material de la represión» (Foucault, 2010: 118).

La iglesia, lejos de censurar esta representación excluyente, ayuda a consolidarla mediante la justificación del internamiento de los pobres que buscan escapar del orden social que se les impone. El confinamiento como práctica

13 En lo que respecta a España, Iffland ha señalado que fue «una pionera en el establecimiento de manicomios en la Europa cristiana» (Iffland, 1999: 162) y cita las condiciones que regulaban, por ejemplo, la administración del Hospital de Inocentes de Sevilla durante el siglo XVII, donde «el alta no era dada por el médico, sino por el administrador, que ostentaba el mayor poder en la institución» (Ibid, 1999: 165) 
de reclusión 'depurativa', económica y precautoria de la sociedad comienza a forjarse en el siglo XVII. Dado que la acusación de pereza tomaba visos éticos, en estas instituciones represoras se imponía el trabajo estéril, sin bases económicas, como ejercicio purificador y aleccionador. El ocio y su elevado grado de sanción social, alcanza entonces prontamente al loco.

Como indica Iffland, a partir del siglo XVI, se comprueba en la sociedad europea la tendencia a considerar la locura sin ropajes trascendentales, reducida a un mero problema social. A ello agrega: «Un efecto secundario de toda esta transición es lo que ocurre con la interacción del loco (y su pariente cercano, el simple) con los estratos sociales elevados» (Iffland, 1999: 341). El loco comienza a ser medido como una moneda de lujo que incide directamente en el prestigio de su dueño: «[...] una forma excelente de ganar favor entre los poderosos era descubrir un loco y enviarlo como regalo» (Ibid, 1999: 344), lo que en la novela de Avellaneda corresponde a la precisa acción ideada por mosén Valentín ${ }^{14}$. Cuando el loco es finalmente domesticado por el poder institucional a manos de un poderoso, su sabiduría latente y su potencialidad subversiva quedan irremediablemente amputadas.

Grosso modo, esta es una de las bases de representaciones sociales que distancian a Avellaneda de su modelo. Mientras para Cervantes la enajenación mental puede ser un medio de conocimiento, para su epígono se trata de un obstáculo del orden social que amerita su proscripción por medio del aparato jurídico.

La prisión del clérigo loco es, pues, resultado de esta última convicción. Tras la exposición de su imbricada erudición, Avellaneda, emulando una vez más el episodio de los galeotes, hace que su héroe solicite la libertad inmediata del condenado. Sin embargo, en este significativo momento deviene la sorpresa. El loco sabio se aproximaba al paradigma cervantino de la reversibilidad, pero bajo su aparente sabiduría yacía una furia física indiscriminada que acaba anulando el valor simbólico de su estado. La reversibilidad que el lector pudo haber presentido en algún momento se aborta con la repentina violencia con que acomete a don Quijote: «[...] sobreviviéndole al loco una

\footnotetext{
14 La exhibición del loco era uno de los hábitos practicados por la nobleza para la publicación de su poder. Como recuerda Sales Dasí (1999), otros eran los torneos y las justas, ocasiones en que los potentados desplegaban sus oropeles ante los menos favorecidos que seguían los desfiles con el testimonio que permitían sus ojos maravillados.
} 
repentina furia, le dio tres o cuatro bocados crueles en ella, asiéndole a la postre el dedo pulgar con los dientes, de suerte que faltó harto poco para cortársela a cercen» (Avellaneda, 2005: 718) ${ }^{15}$.

La agresión es sorpresiva para el caballero, pero quizá no para el lector, que a este andar ya debe haber advertido la inconexión de las exposiciones eruditas y recelado del juicio del encarcelado cuando invoca la propiedad de la quiromancia ${ }^{16}$.

\section{CORDURA Y LOCURA RECOBRADAS}

Este es, a grandes rasgos, el ámbito administrativo judicial que ha decidido la suerte del segundo don Quijote. El ingreso en la institución le es confirmado por el paje del Archipámpano, quien por primera vez alude a la identidad del héroe dirigiéndose a él como Martín Quijada para situarlo en la realidad de la cordura. Este personaje, cuya participación es circunstancial, pero representativa del eje ideológico que supedita al hidalgo-caballero, es el encargado de notificarle el motivo de su confinamiento y de transmitirle con un discurso idéntico al del cura cervantino el deseo de su retorno territorial:

Señor Martín Quijana, en parte está vuesa merced adonde mirarán por su salud persona con el cuidado y caridad posible; y adviertan que en esta casa llegan otros tan buenos como vuesa merced y tan enfermos de su propio mal, y quiere Dios que en breves días salgan curados y con el juicio entero que al entrar les faltaba. Lo mismo confío será de vuesa merced, como vuelva sobre sí y olvide las lecturas y quimeras de los vanos libros de caballerías que a tal extremo le han reducido. Mire por su alma y reconozca la merced que Dios le ha hecho en no permitir muriese por esos caminos a manos de las desastradas ocasiones en que sus locuras le han puesto tantas veces. (Avellaneda, 2005: 719)

\footnotetext{
15 Esta escena parece una auto parodia a la historia de Los felices amantes, en la que se lee: «-[Lo que quiero] No es -respondió don Gregorio- sino una mano de plata, que tales son las blanquísimas de vuestra merced, para besarla por entre esta reja. -Aunque haya sido atrevimiento, señor don Gregorio -replicó la priora-, no dejaré de usar desa llaneza y libertad por haberlo prometido - y sacando de un curioso guante la mano, la metió por la reja, y don Gregorio, loco de contento, la besó, haciendo y diciendo con ella mil amorosas agudezas». (Avellaneda, 2005: 456-457).

16 Este tipo de artes, recordemos, era profundamente desdeñado por Cervantes.
} 
Lo que el paje omite, pero que conocemos por gestión del narrador, es que los internos viven como presos ${ }^{17}$. Los instrumentos de reducción -grilletes, esposas y fierros- son elevadamente simbólicos del poder represivo tanto de prisiones como de manicomios y resumen la representación social que se tiene de don Quijote y el destino que le cabe. El narrador no escatima ocasión para dibujar el significado de este espacio: «mirando a una parte y a otra, vio cuatro o seis aposentos con rejas de hierro, y dentro dellos muchos hombres, de los cuales unos tenían cadenas, otros grillos y otros esposas [...]» (Avellaneda, 2005: 710); «vio a un hombre puesto en tierra en cuclillas, vestido de negro, con un bonete lleno de mugre en la cabeza, el cual tenía cadena al pie y en las dos manos unos sutiles grillos que le servían de esposas» (Avellaneda, 2005: 711). El trato preveía, asimismo, violencias corporales («[...] echalle una muy buena cadena y dalle muy gentiles tundas hasta que tenga seso [...]» (Avellaneda, 2005: 711)), cuya índole, además de castigar, pretendía moralizar. Sello de esta ostentación de poder es la conducta paternalista de don Álvaro hacia don Quijote, que en estas postrimerías asume su cuidado como una responsabilidad personal:

Detúvose Don Álvaro algunos días en Toledo, y aun visitó y regaló a don Quijote y le procuró sosegar cuanto le fue posible, y obligó con no pocas dádivas a que hiciesen lo mesmo a los que sobrestantes de la casa, y encomendó cuanto le fue posible a los amigos graves que tenía en Toledo el mirar por aquel enfermo, pues en ello harían grandísimo servicio a Dios, y a él particularísima merced. (Avellaneda, 2005: 719)

Para los lectores de la segunda parte cervantina la salida del caballero imitativo del cerco hospitalario podría suscitar una inquietud al margen de los datos suministrados por la ficción: ¿habrá concebido Avellaneda la redacción de algún testamento final del caballero? La respuesta debiera ser invariablemente negativa, pues dicha figuración habría significado relativizar en grado sumo la enajenación mental del protagonista. Una de las cláusulas preliminares para que alguien redactara su testamento era la cabalidad de

\footnotetext{
17 A pesar de esta descripción, que sigue el cuadro conforme nos lo presenta Avellaneda, insistimos en la cautela al momento de refutar radicalmente los tratamientos curativos al interior del establecimiento. Román extrae de la propia literatura asomos que sugieren prudencia en lugar de juicios taxativos, como este que recoge de Lope de Vega: « [...] el propio Lope de Vega, vecino varios años de Toledo, decía en Los Comendadores de Córdoba: "Será por curarte el seso / que en Toledo curan tanto. / Al Nuncio quizá te envía / por burlas de buen asiento"» (Román, s/d: 69)
} 
sus facultades mentales, y Avellaneda se ha preocupado permanentemente de confirmarnos no solo que el caballero estaba privado de ellas, sino que, además, se ha encargado de acentuar la expresión de su dolencia y de mostrarla como irreparable y con un guiño de criminalidad.

La cordura recobrada en el desenlace es efímera, y mientras el caballero la goza se encuentra con Sancho, que ya oficia en la corte del Archipámpano, pero de un modo tan ajeno e inesperado para la solidaridad que han edificado los antecedentes cervantinos que llega a resultar patético: «[...] pasando por la corte, vio a Sancho, el cual, como estaba en prosperidad, le dio algunos dineros para que se volviese a su tierra [...]» (Avellaneda, 2005: 720). A estas alturas, el proyecto de don Álvaro parece haberse cumplido, pero el caballero sufre una recaída, con trazos de un desequilibrio reforzado, convocando esta vez, sin saberlo, a una mujer embarazada como escudera. Las andanzas finalizan con don Quijote solitario y con el tópico de la eventualidad de una continuación: «[...] y él, sin escudero, pasó por Salamanca, Ávila y Valladolid, llamándose el Caballero de los Trabajos, los cuales no faltará mejor pluma que los celebre» (Avellaneda, 2005: 721).

De este desenlace se desprenden ciertos acentos ideológicos que se basan en la relación del poder y su percepción de la locura: el loco es un inútil, un ente improductivo que puede sacudir las bases de la verticalidad social. Sus destinos posibles no pueden, pues, sino reducirse a dos: obrar como objeto de esparcimiento para la alta alcurnia; ser confinado en instituciones paracarcelarias. El loco nada enseña, y con él nada se aprende, es un ser supeditado y solitario. Sobre esta última condición, no se debiera olvidar el hecho de que el segundo caballero no solo se queda sin Sancho, sino también sin Rocinante, que muere en la Casa del Nuncio. Descontado el asno del escudero, ambos compañeros -Sancho y Rocinante- conforman lo que podríamos denominar sus contiguos identitarios, vale decir, los seres (humano y animal, que en el caso de Avellaneda tienden a una cierta equidad) que comportan la fundación física y afectiva del caballero. Mientras Sancho cumple como asistente profesional, Rocinante opera como medio de transporte. Eliminados ambos, la figura de don Quijote queda llanamente descaracterizada.

Resta añadir que la sucesión de hechos del desenlace imitativo es altamente concentrada: diversos y complejos hechos ocurren en un espacio narrativo muy acotado. Es probable que con la referida desfiguración del caballero, 
Avellaneda haya presentido que nada quedaba por decir, que su tarea de reconducir a los protagonistas hacia sus propias representaciones ideológicas estaba cumplida y que la historia podía concluirse sin mayores dilaciones, no sin antes, repetimos, valerse del bastión retórico de la continuación, algo que probablemente nunca llegó a concebir ni planificar.

\section{CONSIDERACIONES FINALES}

El análisis del tema tratado en este estudio sugiere que en la novela imitativa no se evidencian variaciones de grado cuanto a la validez de un poder hegemónico y jerárquico, en donde sus representantes participan de un derecho constitutivo para imponer un tipo de mundo y someter al entorno inmediato. El narrador por el que se transmite esta representación social no juzga ni critica las arbitrariedades de los nobles y adhiere sin rodeos a este orden de cosas, convirtiéndose así en vocero no solo del poder político legitimado por la sangre, sino también del eclesiástico, con el cual crea una unidad cómplice y unidireccional. Los resultados de este sustrato de creencias son dos: la naturaleza bufa del aparato ficcional; el estatismo o inmovilidad de los personajes.

Una de las motivaciones posibles de Avellaneda fue componer su obra con base en el rescate de la esencia de decoro prescrita en la comedia horaciana. En conformidad con esta orientación, todos sus personajes, sin excepción, presentan una linealidad de conducta que relativiza las complejidades de la ambigüedad humana. La pareja central no hace de la locura, cordura, sandez y sabiduría términos solidarios y sus diálogos distan en lo esencial de la estatura edificante que les imprimió su antecedente cervantino.

Esta concepción modélica limita la figuración de entresijos ideológicos. Avellaneda demuestra estar convencido de un sistema de representaciones que no discuten el poder sino que lo afianzan y lo promueven como el estrato idóneo para el combate a las señales de movilidad social. De ello parece provenir la falta de cuestionamientos que se revelan, por ejemplo, en los hechos narrados en el capítulo VIII, donde el caballero defiende un amago de justicia desprovista de inspiración ideológica y que se anula a sí misma por efecto de la enajenación mental y social de su vocero. 
Lo propio ocurre en el examen del capítulo final en que nos hemos detenido. En él, Avellaneda muestra signos ideológicos basados en el diálogo entre el poder y la devaluación social de la locura. En este desenlace, la imitación no hace más que corroborar las representaciones sociales que reducen al loco a objeto de esparcimiento de los potentados sin capacidad subversiva ni posibilidad de entendimiento superior.

En las páginas finales quedan consagrados la hegemonía nobiliaria y el confinamiento del orate a un ámbito marginal y ajeno a la sociedad. Con esta declaración ideológica queda, asimismo, confirmada la esencia lineal de la naturaleza de los personajes, sin la cual habrían tenido cabida posibles cuestionamientos al poder a través de quienes lo representan. Avellaneda, en definitiva, reduce los entresijos ideológicos y nos presenta el armazón judicial y social no solo como efectivamente es y procede, sino como presumiblemente debía ser y proceder.

\section{REFERENCIAS BIBLIOGRÁFICAS}

Álvarez Roblin, David (2016), «Propuestas para un nuevo enfoque de la relación Cervantes-Avellaneda», en Hanno Ehrlicher (ed.), El otro Don Quijote. La continuación de Fernández de Avellaneda y sus efectos. Mesa redonda, Nueva Serie Número 33, Augsburgo, Universität Augsburg Institut für Spanien, Portugal- und Lateinamerikastudien (ISLA) Instituto de Investigaciones sobre España, Portugal y América Latina, págs. 93-109. Disponible en https://opus.bibliothek.uni-augsburg.de/opus4/frontdoor/ index/index/docId/3704

Aristóteles (2014), Retórica, Madrid, Alianza.

BLASCO, Javier (2005), «Avellaneda, secular enigma cervantino», en Insula, abril 2005, págs. 700-701. Disponible en http://uvadoc.uva.es/handle/10324/2432 (14/07/2016).

DIJK, Teun van (1999), Ideología. Un enfoque multidisciplinario, Barcelona, Gedisa.

EHRLICHER, Hanno (2016), «La artificiosidad aumentada. Avellaneda como catalizador de la narrativa del Quijote», en Hanno Ehrlicher (ed.), El otro 
Don Quijote. La continuación de Fernández de Avellaneda y sus efectos. Mesa redonda, Nueva Serie Número 33, Augsburgo, Universität Augsburg Institut für Spanien, Portugal- und Lateinamerikastudien (ISLA) Instituto de Investigaciones sobre España, Portugal y América Latina, págs. 55-74. Disponible en https://opus.bibliothek.uni-augsburg.de/opus4/frontdoor/index/index/docId/3704

Fernández de Avellaneda, Alonso (2005), El ingenioso Hidalgo don Quijote de La Mancha, ed. de Luis Gómez Canseco, Barcelona, Editorial Biblioteca Nueva.

- (2014), El ingenioso Hidalgo don Quijote de La Mancha, ed. de Luis Gómez Canseco, Madrid, Real Academia Española.

Foucault, Michel (2010), Historia de la locura en la época clásica, México D.F, Fondo de Cultura Económica.

GutiérRez TRÁPAgA, Daniel (2016), «De los Amadises a los Quijotes: continuación y ciclo en Cervantes y Avellaneda», En Revista Historias Fingidas, volumen 4, págs. 137-155. Disponible en http:/ / historiasfingidas.dlls.univr. it/index.php/hf

IfFLAND, James (1999), De fiestas y aguafiestas: risa, locura e ideología en Cervantes y Avellaneda, Madrid, Iberoamericana.

Martín JimÉneZ, Alfonso (2000), «El Quijote de Cervantes, el Quijote de Avellaneda y la retórica del Siglo de Oro», Separata Edad de Oro, XIX, Madrid, http:/ / uvadoc.uva.es/handle/10324/2075 (14/07/2016).

- (2005). Cervantes y Pasamonte. La réplica cervantina al Quijote de Avellaneda, Madrid, Editorial Biblioteca Nueva.

MARTín MORÁN, José Manuel (2016), «El diálogo en las dos segundas partes del Quijote», en Hanno Ehrlicher (ed.), El otro Don Quijote. La continuación de Fernández de Avellaneda y sus efectos. Mesa redonda, Nueva Serie Número 33, Augsburgo, Universität Augsburg Institut für Spanien, Portugal- und Lateinamerikastudien (ISLA) Instituto de Investigaciones sobre España, Portugal y América Latina, págs. 75-92. Disponible en https://opus.bibliothek.uniaugsburg.de/opus4/frontdoor/index/index/docId/3704 
Riorda, Mario y FARré, Marcela (2012), ¡Ey, las ideologías existen. Comunicación política y campañas electorales en América Latina, Buenos Aires, Biblos.

Román, Rafael Sancho de San (s/d), El hospital del Nuncio de Toledo en la historia de la asistencia psiquiátrica, http:/ / www.realacademiatoledo.es/files/ anales/0017/04.pdf (01/09/2016).

SALES Dasí, Emilio (1999), «"Ver" y “mirar" en los libros de caballerías», en THESAVRVS-Boletín del Instituto Caro y Cuervo, 54.1, http:/ / cvc.cervantes.es/lengua/thesaurus/pdf/54/TH_54_001_017_0.pdf (19/10/2015).

Žı̌̌EK, Slavoj (org.) (2013), Um mapa da ideologia, Rio de Janeiro, Contraponto. 